\title{
Interventions for cannabis misuse
}

\author{
Clementine Maddock \& Michelle Babbs
}

\begin{abstract}
Cannabis is the most commonly used illicit drug in the UK and a significant proportion of users have symptoms of dependence. In addition, there are a number of adverse consequences of use, including an association with psychotic disorders. Thus there is a need for effective treatment of cannabis misuse. Psychological therapies have been developed based on principles of motivational interviewing, cognitive-behavioural therapy and relapse prevention. The evidence base for these therapies is explored in this review, and studies targeting both adult users and young people are considered. Possible new pharmacological treatments are also discussed.
\end{abstract}

Research suggests that people enjoy smoking cannabis. The drug is taken for relaxation and as a social activity (Green et al, 2004), and is the most commonly used illicit drug in the UK: one-quarter of 16- to 24year-olds and $11 \%$ of 16 - to 59 -year-olds have used cannabis in the past year (Chivite-Matthews et al, 2005). Cannabis is undoubtedly popular but a significant proportion of users experience symptoms of dependence (Box 1). The National Household Survey found that $10 \%$ of British adults had tried cannabis and $3 \%$ had at least one symptom of dependence (Coulthard et al, 2002). This is in addition to other harmful effects, in particular the association with the development of psychotic illness. The widespread use and potential for harm indicate a need for treatments for cannabis misuse.

\section{How harmful is cannabis?}

'Occasionally and in small doses hashish perhaps does not offer much danger' stated Dr Mohamed Abdel Salam El Guindy, an Egyptian physician, at a League of Nations conference in 1924 (Kendell, 2003). He described acute intoxication as a 'state of delirium ... which takes a violent form in a person of violent character'. With chronic use 'intellectual faculties gradually weaken and the organism decays. The addict very frequently becomes neurasthenic and, eventually, insane'. However, 'in persons of a cheerful disposition' intoxication merely produced 'a kind of hilarious and noisy delirium'. His speech was key in persuading delegates that cannabis should be subject to international narcotics legislation.

\section{Box 1 A summary of ICD-10 criteria for} dependence

Three or more of the following criteria should be present for at least 1 month, or repeatedly over a 12-month period:

- compulsion to use the substance

- difficulty controlling the level of substance use

- withdrawal symptoms or use of the substance to reduce withdrawal symptoms

- tolerance to the effects of the substance

- primacy of substance use over other activities

- persistent substance use despite clear evidence of harmful consequences

(World Health Organization, 1992)

A more recent review of the harmful effects of cannabis concluded that

\begin{abstract}
'the long term use of cannabis, particularly at high intake levels, is associated with severe adverse psychosocial features, including lower educational achievement and, in some instances, psychiatric illness. There is little evidence, however, that long-term cannabis use causes permanent cognitive impairment, nor is there any clear cause and effect relationship to explain the psychosocial associations' (Iversen, 2005).
\end{abstract}

In the UK, cannabis has been the subject of two government reviews, and was downgraded from a class $B$ to a class $C$ drug because it was deemed

Clementine Maddock is a specialist registrar at the Maudsley Hospital (Denmark Hill, London SE5 8AZ, UK. Email: c.maddock@iop.kcl. ac.uk) training in general adult and addiction psychiatry. She has published research on the assessment of mental capacity, psychiatric side-effects of hepatitis C, and dual diagnosis. Her current interests include interventions for substance misuse. Michelle Babbs is a clinical psychologist at the Lambeth Cannabis Clinic in London. She has an interest in developing psychological interventions for cannabis users in the UK. 
less harmful to individuals and society than other illicit substances (Advisory Council on the Misuse of Drugs (ACMD) 2002, 2005). Nevertheless, the ACMD concluded that there should be more research into the treatment of cannabis dependency and the availability of such services.

\section{Psychological therapies for misuse}

Psychological treatments for cannabis misuse have been developed and are based on those for alcohol and other drug dependence. These often utilise components of motivational interviewing (Miller \& Rollnick, 2002), cognitive-behavioural therapy (CBT; Wright et al, 1993) and relapse prevention (Marlatt \& Gordon, 1985). These approaches aim to enhance clients' motivation to change, give them coping strategies for dealing with difficulties such as low mood, and teach them to predict and challenge cravings in order to prevent relapse.

\section{Motivational intervierwing}

The aim of motivational interviewing is to enhance a client's own internal drivers for change. Miller \& Rollnick (2002) have described the following four basic principles of the technique (Box 2). The principles of motivational interviewing form the basis for motivational enhancement therapy (MET).

\section{Express empathy}

The therapist seeks to understand the client's feelings and perspectives without judging, criticising or blaming. Through skilful reflective listening the counsellor clarifies and accepts the clients' feelings and perspective, although not necessarily agreeing with or endorsing their point of view. Ambivalence towards change is seen as a normal part of human experience.

\section{Develop discrepancy}

Motivational interviewing aims to move clients from ambivalence towards positive behavioural change by

\section{Box 2 The four basic principles of motivational interviewing}

- Express empathy

- Develop discrepancy

- Roll with resistance

- Support self-efficacy

(Miller \& Rollnick, 2002) developing discrepancy between the client's current behaviour and future goals. The client, guided by the counsellor, should voice their own arguments for change.

\section{Roll with resistance}

Behaviours that may indicate resistance to change are a signal for the therapist to change tack. Rather than arguing for change or directly opposing the client's views, the therapist might invite the client to offer new perspectives on their misuse. There is a danger that if the therapist tries to find solutions for the client she will be met with a 'yes, but...' response. It might be better to turn the question or problem back to the client and so involve them in finding their own solutions.

\section{Support self-efficacy}

Self-efficacy refers to a person's belief in their ability to carry out and succeed with a specific task. Both the client's and therapist's belief in the possibility of change are important motivators and predictors of change. The client, not the therapist, is responsible for making changes.

These four techniques can enhance a client's motivation to continue with treatment and alter their drug-using behaviour. For the client to accomplish this, the beliefs that maintain the cycle of addiction need to be addressed. Certain types of belief are pertinent in addictive behaviour (Wright et al, 1993). Addictive beliefs (e.g. belief in needing substances to maintain psychological balance, for the relief of low mood and to gain pleasure) are common. They may be activated in high-risk situations, including low mood states or when confronted with people and places associated with drug use. Relief-oriented beliefs such as 'I need cannabis to feel normal' may then develop. Permission-giving beliefs such as 'Everyone else is using' and 'I deserve it' may then justify acquiring and using cannabis. Ambivalence may result from the conflict between such permission-giving beliefs and thoughts of abstinence. This can then trigger relief-oriented beliefs ('I need cannabis to feel normal') and tip the balance in favour of using. Underlying core beliefs may result in vulnerability to the development of problematic substance-using behaviour.

\section{Relapse prevention}

A relapse prevention programme (Marlatt \& Gordon, 1985) based on CBT enables clients to cope with high-risk situations. Components of the programme are shown in Box 3. 
Box 3 Components of a relapse prevention programme

- Identification of high-risk situations and triggers for cravings

- How to say no to buying or using cannabis; role-play may be used

- Development of skills to cope with cravings, e.g. self-talk, distracting activities; clients might keep a diary to document how cravings are managed

- Identifying alternative pleasurable activities

- Learning to cope with lapses; clients may develop a personal emergency plan to identify steps for dealing with relapse

- Management of low mood and anger using problem-solving skills and relaxation training; identification and modification of negative thoughts

- Creation of a personal self-help sheet documenting the benefits of not using cannabis, risks of using and high-risk situations

(Marlatt \& Gordon, 1985)

\section{Psychological therapies in practice}

The following fictional case example, based on clinical experience, illustrates how psychological techniques may work in practice.

\section{Case example}

John, a 36-year-old unemployed man, was referred to a local cannabis service by his general practitioner. He reported smoking ten joints of 'skunk' cannabis each day, usually alone. He also described feeling low in mood. John's goal was to stop smoking cannabis completely. He was offered six sessions of motivational interviewing and CBT.

Throughout the intervention a non-judgemental and empathic motivational interviewing style was adopted to help John identify his own reasons for stopping his cannabis use. John recognised that he smoked cannabis in an attempt to 'chill out', although he found that it made 'everything an effort' and so prevented him from living life as he wished to. He was particularly keen to undertake a college course and to socialise more often. John said that the importance to him of stopping was high, but his confidence that he could do so was low. The therapist supported John's self-efficacy by eliciting a past strength: John had succeeded in giving up cigarettes. Remembering this helped to increase his confidence that he could stop smoking cannabis.

John gradually reduced his cannabis use by using coping strategies known as the four Ds: delaying, distraction, de-catastrophising and de-stressing. John delayed his first joint of the day for as long as possible, and found physical exercise to be an enjoyable distraction. In addition, John repeated to himself some 'de-catastrophising' statements; for example, 'I'm not going to die if I don't have a joint'. He found other ways to 'de-stress' and hence to relax. John also completed records of his thoughts. These records detailed the situations in which he used cannabis and his negative thoughts at these times, so that these could be challenged and replaced with positive thoughts.

After six sessions John had successfully managed to stop smoking cannabis. To reduce the risk of relapse, high-risk situations for cannabis use were identified, and activities and thoughts that could help him to cope with any cravings at these times were explored. As well as stopping his cannabis use, John enrolled on an information technology course at his local college and started swimming regularly. He reported feeling much happier and more optimistic about his future, and confident that he could continue to abstain from cannabis use.

\section{The evidence for psychological interventions \\ Adults}

There have been five controlled trials of psychological treatments for adults who misuse cannabis (for details see Table 1). The interventions tend to combine motivational interviewing and therapies based on cognitive-behavioural principles such as relapse prevention and coping skills. Stephens and colleagues (1994) conducted the first randomised controlled trial for cannabis misuse. They recruited their participants through advertisements and randomised them to group sessions of social support or of relapse prevention. Nearly two-thirds reported abstinence during the final 2 weeks of the treatment period. However, only $14 \%$ reported sustained abstinence throughout the 12-month follow-up period, with no difference between the two treatment groups. This team conducted a second trial (Stephens et al, 2000), again recruiting through newspaper adverts, in which they randomised participants to one of three arms: group sessions of relapse prevention, two sessions of individual treatment or delayed treatment (control). Once again the outcomes were similar with both active treatments: an impressive 30\% reported abstinence over the 90 days preceding the 16-month follow-up and $22 \%$ reported sustained abstinence over the previous 12 months. However, the fact that, at 4-month followup, $9 \%$ of the delayed-treatment control group were also abstinent perhaps reflects the motivation of the self-selected sample.

Further evidence for the effectiveness of cognitivebehavioural approaches is provided by Copeland 


\begin{tabular}{|c|c|c|c|c|}
\hline Study & $\begin{array}{l}\text { Type of trial } \\
\text { (sample size) }\end{array}$ & Active treatment & Control & Outcomes \\
\hline Stephens et al (1994) & $\operatorname{RClT}(n=212)$ & $\begin{array}{l}10 \text { weeks' social sup- } \\
\text { port } v .10 \text { weeks' relapse } \\
\text { prevention }\end{array}$ & None & $\begin{array}{l}14 \% \text { reported sustained abstinence } \\
\text { at } 12 \text {-month follow-up in both } \\
\text { treatment groups }\end{array}$ \\
\hline Stephens et al (2000) & $\operatorname{RCT}(n=291)$ & $\begin{array}{l}14 \text { sessions of relapse } \\
\text { prevention } v .2 \text { sessions } \\
\text { of individual treatment }\end{array}$ & $\begin{array}{l}\text { Delayed } \\
\text { treatment }\end{array}$ & $\begin{array}{l}22 \% \text { reported sustained abstinence } \\
\text { at } 12 \text {-month follow-up in both } \\
\text { treatment groups. } 9 \% \text { of controls } \\
\text { abstinent at } 4 \text {-month follow-up }\end{array}$ \\
\hline Budney et al (2000) & $\operatorname{RClT}(n=60)$ & $\begin{array}{l}\text { 14-week study, voucher } \\
\text { incentive+CBT+MET } \\
\text { v. CBT+MET v. MET }\end{array}$ & None & $\begin{array}{l}\text { 30-day abstinence rates at end of tri- } \\
\text { al were } 35 \% \text { in voucher }+ \text { CBT }+ \text { MET } \\
\text { group, } 10 \% \text { in CBT+MET group and } \\
5 \% \text { in MET group }\end{array}$ \\
\hline Copeland et al (2001) & $\operatorname{RCT}(n=229)$ & $\begin{array}{l}6 \text { sessions of } \mathrm{CBT}+\mathrm{MET} \\
\text { v. } 1 \text { session } \mathrm{CBT}\end{array}$ & $\begin{array}{l}\text { Delayed } \\
\text { treatment }\end{array}$ & $\begin{array}{l}15 \% \text { of } 6 \text {-session group, } 5 \% \text { of } 1- \\
\text { session group and } 0 \% \text { of controls } \\
\text { reported sustained abstinence at } \\
\text { 8-month follow-up }\end{array}$ \\
\hline $\begin{array}{l}\text { Marijuna Treatment } \\
\text { Project Research } \\
\text { Group (2004) }\end{array}$ & $\operatorname{RCT}(n=450)$ & $\begin{array}{l}9 \text { sessions of MET+CBT } \\
v .2 \text { sessions of MET }\end{array}$ & $\begin{array}{l}\text { Delayed } \\
\text { treatment }\end{array}$ & $\begin{array}{l}23 \% \text { of } 9 \text {-session group, } 9 \% \text { of } 2- \\
\text { session group and } 4 \% \text { of controls } \\
\text { reported sustained abstinence at } \\
\text { 4-month follow-up }\end{array}$ \\
\hline
\end{tabular}

CBT, cognitive-behavioural therapy; MET, motivational enhancement therapy; RCIT, randomised clinical trial; RCT, randomised controlled trial

et al (2001), who compared six sessions of CBT plus motivational interview with one session of CBT and a delayed-treatment control. Again, both therapy groups reported higher rates of continuous abstinence during the 8-month follow-up period (15\% of the group receiving six sessions, $5 \%$ of the group receiving one session) than the delayedtreatment group ( $0 \%$ abstinent).

Budney et al (2000) found that combining psychological therapies with voucher incentives (contingency management) resulted in greater abstinence than psychological treatment alone. Vouchers were given for each cannabinoid-free weekly urine sample. During the final week of treatment, $35 \%$ of the group receiving combined vouchers, CBT and motivational enhancement therapy (MET) group had been abstinent for 30 days, compared with $10 \%$ of the group receiving combined CBT and MET group, and 5\% of those receiving $\mathrm{MET}$ alone. The difference in abstinence rates between the CBT/MET and MET groups was not statistically significant, perhaps because of the small number of participants (20 in each group).

The largest intervention trial in adults to date, the Marijuana Treatment Project Research Group (2004), compared two sessions of MET, nine sessions of therapy incorporating MET, CBT and case management, and a delayed-treatment control. At 4-month follow-up, abstinence rates were higher for the nine-session intervention $(22.6 \%)$ than for the two-session (8.6\%) (delayed-treatment control 3.6\%). By 15-month follow-up, $22.7 \%$ of the nine-session group reported 90 days of abstinence compared with $12.5 \%$ of the two-session group. These figures are not just explained by loss to follow-up of heavy cannabis users, as follow-up rates were $89 \%$ at 4 months and $83 \%$ at 15 months. Participants were paid US $\$ 50$ for the 4-month follow-up interview and US $\$ 25$ for the 15-month telephone interview. Other measures of cannabis dependence and misuse also improved with treatment.

These studies demonstrate that fairly brief interventions are effective in helping users to stop or reduce their use of cannabis. Nevertheless, the vast majority of participants continue to use at the end of treatment.

\section{Young people \\ Targeted population studies}

Adolescents are of particular interest to researchers involved in treating cannabis use, because they have some of the highest levels of use (Chivite-Matthews et al, 2005) and there is ongoing debate as to whether cannabis is a 'gateway' drug that leads to the use of harder drugs. Young people also have a more interdependent social structure and interventions need to take account of the involvement of the family and school. Two brief intervention studies have 
Table 2 Brief psychological treatments for substance misuse in adolescents recruited from the general population

\begin{tabular}{|c|c|c|c|c|}
\hline Study & $\begin{array}{l}\text { Type of trial } \\
\text { (sample size) }\end{array}$ & Active treatment & Control & Outcome \\
\hline $\begin{array}{l}\text { McCambridge \& } \\
\text { Strang (2004) }\end{array}$ & $\begin{array}{l}\text { Cluster RCT } \\
(n=200)\end{array}$ & $\begin{array}{l}1 \text { session individual } \\
\text { motivational } \\
\text { enhancement therapy }\end{array}$ & $\begin{array}{l}\text { Non-intervention } \\
\text { education as usual }\end{array}$ & $\begin{array}{l}\text { Reduced use of cigarettes, } \\
\text { alcohol and cannabis in MET } \\
\text { group at 3-month follow-up }\end{array}$ \\
\hline Martin et al (2005) & $\begin{array}{l}\text { Uncontrolled } \\
\text { pre-test/post-test } \\
\text { design }(n=73)\end{array}$ & $\begin{array}{l}3 \text { sessions } \\
\text { (assessment, MET, } \\
\text { relapse prevention) } \\
\text { plus family education }\end{array}$ & None & $\begin{array}{l}17 \% \text { reported total abstinence } \\
\text { at } 3 \text {-month follow-up }\end{array}$ \\
\hline
\end{tabular}

been reported (Table 2) and these are noteworthy for targeting young people who are not within a treatment environment.

McCambridge \& Strang (2004) reported reductions in the use of cannabis, cigarettes and alcohol among young people in the UK after just one session of motivational interviewing. The participants, who were aged 16-20 years, had been using cannabis or stimulants weekly for the previous 3 months and were recruited from further education colleges in London. In individual motivational interviews the participants and interviewer discussed the range of drugs used and the interviewer focused on particular areas of risk or concern. Pros and cons of each drug were discussed to stimulate thinking about drug use and promote 'change-talk' (Miller \& Rollnick, 2002). Almost half of the participants discussed changing an aspect of use during their interview. At 3-month follow-up the intervention group were using cannabis a mean of 5.4 times a week compared with 15.7 before the interview. The control group were using cannabis more frequently: 16.9 times a week compared with 13.3 at baseline. At 3 months post-treatment $16 \%$ of the intervention group were abstinent from cannabis compared with $5 \%$ of the control group.

Martin et al (2005) targeted young people in Australia, aged 14-19 years, through media stories and advertising. The intervention consisted of up to three sessions for the participant and an education and communication skills session for concerned others, including parents. An assessment of substance use, pros and cons of use, and perception of risks associated with cannabis was conducted during the first session. During the second session, 1 week later, feedback was given and this information was used to guide a motivational interview. The optional third session included a discussion of cannabis dependence, recognition of personal triggers, managing craving, goal-setting and relapse prevention. At 3-month follow-up more than three-quarters of those interviewed reported either a reduction in use or abstinence from cannabis, although in keeping with adult studies a minority (16\%) achieved abstinence.

\section{Studies within drug-treatment settings}

So, brief interventions taken to populations who may not otherwise have sought help can be effective. But how do young people fare with longer treatments in more traditional settings? The Drug Abuse Treatment Outcome Studies for Adolescents (DATOS-A; Hser et al, 2001) recruited 1167 adolescents (age 11-18 years), used a naturalistic, non-experimental evaluation design and assessed outcomes for interventions commonly used in the USA. This study has the particular advantage of a 'real world' population who have coexistent polydrug use, mental disorders, criminal activity and associated family and social problems. Three broad types of intervention were available: (a) residential treatment programmes consisting of counselling, family therapy and living within a therapeutic community, typically lasting 3-12 months (median 5 months); (b) outpatient drug-free programmes with components of individual, group and family therapy, lasting 1-6 months (median 1.6 months); and (c) short-term medically supervised in-patient programmes, again including individual and group counselling, family therapy and also '12-step' sessions. These lasted 5-35 days (median 18 days) and patients were typically referred for out-patient treatment on discharge.

Although the interventions were not specifically targeted at cannabis users, nearly half of the participants reported this as their primary drug problem, and $80.4 \%$ reported weekly cannabis use; this declined to $43.8 \%$ at 1 -year post-treatment followup. There were also significant improvements in psychological adjustment (as measured by suicidal thoughts, hostility and self-esteem), school performance and criminal activity in the year after treatment. Participants who spent more time in treatment were more likely to have abstained from any drug or alcohol use.

Although the DATOS-A results demonstrate treatment effectiveness, they do not indicate which 
modalities of treatment are most beneficial for cannabis misuse. The Cannabis Youth Treatment study (CYT; Dennis et al, 2004) sought to address this. Five out-patient therapies for adolescents with cannabis use disorders were compared for clinicaland cost-effectiveness. The interventions were: (a) 2 individual sessions of MET and 3 group CBT sessions; (b) 2 individual MET sessions and 10 group CBT sessions; (c) as for (b) plus 6 parent education group meetings, 4 therapeutic home visits, referral to self-help support groups and case management; (d) 10 individual sessions with the participant, 4 sessions with caregivers and case management; these sessions included a functional analysis of the drug-seeking behaviour and communication and problem-solving sessions with the family; (e) multidimensional family therapy consisting of 6 individual sessions with the participant, 3 parental sessions and 6 family meetings.

Six hundred adolescents and their families were recruited and randomised from sequential admissions to four drug treatment sites in the USA. At 1-year follow-up 24\% were in recovery, defined as no substance use in the past month. Treatment (a) (5 sessions MET plus CBT), one of the shortest interventions, had the highest proportion of adolescents in recovery $(27 \%)$, although the clinical outcomes were similar across all conditions. Interventions (a), (b) and (d) were the most costeffective. It is interesting that the shortest therapy was so effective in view of the results from the DATOS-A favouring longer treatments. The populations differ in terms of comorbidity and other social factors, but the CYT study suggests that certain populations can benefit from relatively brief interventions.

\section{Treatment of comorbid cannabis use and psychosis}

Cannabis intoxication can lead to acute transient psychotic episodes (D'Souza et al, 2004) and cannabis use increases the risk of relapse in people with schizophrenia (Treffert, 1978; Turner \& Tsuang, 1990). There is now more evidence of the association between cannabis use and onset of psychotic disorders, the most rigorous of which has been reviewed by Arsenault et al (2004). They identified five prospective cohort studies and calculated that cannabis use confers an overall twofold increase in the relative risk for schizophrenia. It seems that cannabis use accelerates the onset of psychosis in vulnerable individuals: schizophrenia is identified at a younger age in people with a previous diagnosis of cannabis-induced psychotic disorders (Arendt $e t$ $a l, 2005)$. Genetic factors may be partly responsible for this increased vulnerability. Caspi and colleagues
(2005) have identified a polymorphism in the catechol-O-methyl transferase (COMT) gene as a potential mediator for the increased risk of psychotic illness following cannabis use.

Despite the evidence of harmful effects of cannabis in people who have been diagnosed with, or who have a vulnerability for, psychotic disorders, there are few studies investigating the treatment of substance use in this group. Haddock and colleagues (2003) conducted the first randomised controlled trial of a motivational intervention, individual CBT and a family intervention in people with schizophrenia and comorbid substance misuse. Although not specifically targeting cannabis use, a significant proportion of participants used this drug. The treatment group had a greater percentage of days abstinent relative to baseline than the control group, although this difference did not achieve statistical significance. At 18-month follow-up there were significant improvements in overall functioning and negative symptom scores in the intervention group.

A larger study compared CBT and motivational interviewing with treatment as usual in people with a psychotic disorder and hazardous alcohol, cannabis and/or amphetamine use (Baker et al, 2006). Once again, although there was a trend for a reduction in cannabis consumption between the baseline and 15-week assessments for the treatment group compared with control group, this was not statistically significant and there was no differential benefit of the intervention on substance use at 12 months. There may be a potential benefit of atypical antipsychotics, in particular clozapine, in reducing the use of alcohol, cannabis, cocaine and tobacco by people with schizophrenia (Green, 2005).

\section{Pharmacological therapies - the future?}

Pharmacotherapy for cannabis misuse is in its infancy. We have found just one controlled trial to date. Levin and colleagues (2004) compared divalproex sodium with placebo in clients with cannabis dependence. Participants in both groups were also given psychological treatment. At the end of the trial modest reductions in cannabis use were seen in both groups, suggesting that divalproex sodium had no specific beneficial effect. There are some suggestions that fluoxetine and buspirone are associated with reduced cannabis use, and nefazadone may help alleviate withdrawal symptoms (McRae et al, 2003). In the future, there may be therapeutic use of cannabinoid receptor antagonists, which have been shown to block the acute physiological and psychological effects of smoking cannabis (Huestis et al, 2001). 


\section{Conclusions}

Despite the popularity of cannabis use, there is only a sparse evidence base supporting interventions for the significant proportion of users who require treatment for dependence or its adverse effects. Psychological therapies using motivational interviewing, cognitive-behavioural and relapse prevention techniques have been developed and evaluated in a few studies involving both adults and young people. They seem to be effective in reducing use, with about one-fifth of participants achieving abstinence. However, many of these studies were conducted in the USA and Australia and there is a need for further UK-based research. Pharmacological therapies for cannabis misuse have been little studied. The challenge now is to translate such trial data as there is into interventions that are available in everyday clinical practice.

\section{Declaration of interest}

None.

\section{References}

Advisory Council on the Misuse of Drugs (2002) The Classification of Cannabis under the Misuse of Drugs Act 1971. London: Home Office.

Advisory Council on the Misuse of Drugs (2005) Further Consideration of the Classification of Cannabis under the Misuse of Drugs Act 1971. London: Home Office.

American Psychiatric Association (1994) Diagnostic and Statistical Manual of Mental Disorders (4th edn). Washington: American Psychiatric Association.

Arendt, M., Rosenberg, R., Foldager, L., et al (2005) Cannabisinduced psychosis and subsequent schizophrenia-spectrum disorders: follow-up study of 535 incident cases. British Journal of Psychiatry, 187, 510-515.

Arseneault, L., Cannon, M., Witton, J., et al (2004) Causal association between cannabis and psychosis: examination of the evidence. British Journal of Psychiatry, 184, 110-117.

Baker, A., Bucci, S., Lewin, T. J., et al (2006) Cognitive-behavioural therapy for substance use disorders in people with psychotic disorders. British Journal of Psychiatry, 188, 439-448.

Budney, A. J., Higgins, S. T., Radanovich, K. J., et al (2000) Adding voucher-based incentives to coping skills and motivational enhancement improves outcomes during treatment for marijuana dependence. Journal of Consulting and Clinical Psychology, 68, 1051-1061.

Caspi, A., Moffitt, T. E., Cannon, M., et al (2005) Moderation of the effect of adolescent-onset cannabis use on adult psychosis by a functional polymorphism in the catechol-Omethyltransferase gene: longitudinal evidence of a gene $x$ environment interaction. Biological Psychiatry, 57, 1117-1127.

Chivite-Matthews, N., Richardson, A., O'Shea, J., et al (2005) Drug Misuse Declared: Findings from the 2003/04 British Crime Survey. London: Home Office.

Copeland, J., Swift, W., Roffman, R., et al (2001) A randomised controlled trial of brief cognitive-behavioural interventions for cannabis use disorder. Journal of Substance Abuse Treatment, 21, 55-64

Coulthard, M., Farrell, M., Singleton, N., et al (2002) Tobacco, Alcohol and Drug Use and Mental Health. London: TSO (The Stationery Office).
Dennis, M., Godley, S., Diamond, G., et al (2004) The Cannabis Youth Treatment (CYT) study: main findings from two randomized trials. Journal of Substance Abuse Treatment, 27, 197-213.

D'Souza, C., Cho, H. S., Perry, E., et al (2004) A cannabinoid model psychosis, dopamine-cannabinoid interactions and implications for schizophrenia. In Marijuana and Madness (eds D. J. Castle \& R. Murray), pp. 142-165. Cambridge: Cambridge University Press.

Green, A. (2005) Schizophrenia and comorbid substance use disorder: effects of antipsychotics. Journal of Clinical Psychiatry, 66 (suppl. 6), 21-26

Green, B., Kavanagh, D. J. \& Young, R. M. (2004) Reasons for cannabis use in men with and without psychosis. Drug and Alcohol Review, 23, 445-453.

Haddock, G., Barrowclough, C., Tarrier, N., et al (2003) Cognitivebehavioural therapy and motivational intervention for schizophrenia and substance misuse: 18-month outcomes of a randomised controlled trial. British Journal of Psychiatry, 183, $418-426$.

Hser, Y., Grella, C. E., Hubbard, R. L., et al (2001) An evaluation of drug treatments for adolescents in 4 US cities. Archives of General Psychiatry, 58, 689-695.

Huestis, M. A., Gorelick, D. A., Heishman, S. J., et al (2001) Blockade of effects of smoked marijuana by the CB1-selective cannabinoid receptor antagonist SR141716. Archives of General Psychiatry, 58, 322-328.

Iversen, L. (2005) Long-term effects of exposure to cannabis. Current Opinion in Pharmacology, 5, 69-72.

Kendell, R. (2003) Cannabis condemned: the proscription of Indian Hemp. Addiction, 98, 143-151.

Levin, F. R., McDowell, D., Evans, S. M., et al (2004) Pharmacotherapy for marijuana dependence: a double-blind, placebo-controlled pilot study of divalproex sodium. American Journal of Addiction, 13, 21-32.

Marijuana Treatment Project Research Group (2004) Brief treatments for cannabis dependence: findings from a randomized multisite trial. Journal of Consulting and Clinical Psychology, 72, 455-466.

Marlatt, G. A. \& Gordon, J. R. (1985) Relapse Prevention: A SelfControl Strategy for the Maintenance of Behaviour Change. New York: Guilford Press.

Martin, G., Copeland, J. \& Swift, W. (2005) The Adolescent Cannabis Check-Up: feasibility of a brief intervention for young cannabis users. Journal of Substance Abuse Treatment, 29, 207-213.

McCambridge, J. \& Strang, J. (2004) The efficacy of single-session motivational interviewing in reducing drug consumption and perceptions of drug-related risk and harm among young people: results from a multi-site cluster randomised trial. Addiction, 99, 39-52.

McRae, A. L., Budney, A. J. \& Brady, K. T. (2003) Treatment of marijuana dependence: a review of the literature. Journal of Substance Abuse Treatment, 24, 369-376.

Miller, W. R. \& Rollnick, S. (2002) Motivational Interviewing: Preparing People for Change. New York: Guilford Press.

Stephens, R. S., Roffman, R. A. \& Simpson, E. E. (1994) Treatment of adult marijuana dependence: a test of the relapse prevention model. Journal of Consulting and Clinical Psychology, 62, 9299.

Stephens, R. S., Roffman, R. A. \& Curtin, L. (2000) Comparison of extended versus brief treatments for marijuana use. Journal of Consulting and Clinical Psychology, 68, 898-908.

Treffert, D. (1978) Marijuana use in schizophrenia: a clear hazard. American Journal of Psychiatry, 135, 1213-1215.

Turner, W. M. \& Tsuang M. T. (1990) Impact of substance abuse on the course and outcome of schizophrenia. Schizophrenia Bulletin, 16, 1990.

World Health Organization (1992) The ICD-10 Classification of Mental and Behavioural Disorders: Clinical Descriptions and Diagnostic Guidelines. Geneva: WHO.

Wright, F. D., Beck, A. T., Newman, C. F., et al (1993) Cognitive Therapy of Substance Abuse. New York: Guilford Press. 


\section{MCQs}

1 Cannabis:

a has been used by $25 \%$ of the UK population in the past year

b has been used by $25 \%$ of 16 - to 24 -year-olds in the past year

c dependence occurs in a minority of users

$\mathrm{d}$ is a class B drug within UK legislation

e use is associated with normal educational achievement.

2 Use of cannabis is associated with:

a permanent cognitive impairment

b acute psychotic episodes

c increased risk of relapse in people with schizophrenia

d a five-times increased relative risk for schizophrenia

e later age at onset of schizophrenia.

3 Psychological treatments for cannabis misuse:

a use principles of motivational interviewing

b use principles of cognitive-behavioural therapy

c use principles of relapse prevention

d do not teach clients how to manage associated mood symptoms

e do not consider how to cope with a relapse, as this is unlikely to occur.

4 When treating adult cannabis misuse:

a about $80 \%$ of clients will be abstinent at follow-up

b about $80 \%$ of clients will still be using at follow-up

c adding voucher incentives is no more effective than psychological treatment alone

d longer therapies are much more effective than shorter

e single-session treatments are ineffective.

5 In trials of interventions for young people with cannabis misuse:

a interventions are only effective in young people attending treatment centres

b single-session interventions can reduce cannabis use

c the family should not be involved in the treatment

d treatment has no effect on criminal activity

e cognitive-behavioural therapy and motivational interviewing are the only effective treatments.

\section{MCQ answers}

$\begin{array}{lllllll}\text { 1 } & & \text { 2 } & & 3 & 4 & 5 \\ \text { a F } & \text { a F } & \text { a T } & \text { a F } & \text { a F } \\ \text { b T } & \text { b T } & \text { b T } & \text { b T } & \text { b T } \\ \text { c T } & \text { c T } & \text { c T } & \text { c F } & \text { c F } \\ \text { d F } & \text { d F } & \text { d F } & \text { d F } & \text { d F } \\ \text { e F } & \text { e F } & \text { e F } & \text { e F } & \text { e F }\end{array}$

